\title{
Methylammonium methylcarbamate thermal formation in interstellar ice analogs: a glycine salt precursor in protostellar environments
}

\author{
J.-B. Bossa ${ }^{1}$, F. Duvernay ${ }^{1}$, P. Theulé ${ }^{1}$, F. Borget ${ }^{1}$, L. d'Hendecourt ${ }^{2}$, and T. Chiavassa ${ }^{1}$ \\ ${ }^{1}$ Laboratoire de Physique des Interactions Ioniques et Moléculaires (PIIM), Université de Provence et CNRS, UMR6633, \\ Centre de Saint-Jérôme, Case 252, Avenue Escadrille Normandie-Niémen, 13397 Marseille, France \\ e-mail: Jean-Baptiste.Bossa@etu.univ-provence.fr \\ 2 Institut d'Astrophysique Spatiale (IAS), UMR8617, CNRS, Bât 121, Université Paris-Sud, 91405 Orsay Cedex, France
}

Received 8 July 2009 / Accepted 22 July 2009

\begin{abstract}
Context. Analyses of dust cometary grains collected by the Stardust spacecraft have shown the presence of amines and amino acids molecules, and among them glycine $\left(\mathrm{NH}_{2} \mathrm{CH}_{2} \mathrm{COOH}\right)$. We show how the glycine molecule could be produced in the protostellar environments before its introduction into comets.

Aims. We study the evolution of the interstellar ice analogues affected by both thermal heating and vacuum ultraviolet (VUV) photons, in addition to the nature of the formed molecules and the confrontation of our experimental results with astronomical observations. Methods. Infrared spectroscopy and mass spectrometry are used to monitor the evolution of the $\mathrm{H}_{2} \mathrm{O}: \mathrm{CO}_{2}: \mathrm{CH}_{3} \mathrm{NH}_{2}$ and $\mathrm{CO}_{2}: \mathrm{CH}_{3} \mathrm{NH}_{2}$ ice mixtures during both warming processes and VUV photolysis.

Results. We first show how carbon dioxide $\left(\mathrm{CO}_{2}\right)$ and methylamine $\left(\mathrm{CH}_{3} \mathrm{NH}_{2}\right)$ thermally react in water-dominated ice to form methylammonium methylcarbamate $\left[\mathrm{CH}_{3} \mathrm{NH}_{3}^{+}\right]\left[\mathrm{CH}_{3} \mathrm{NHCOO}^{-}\right]$noted $\mathrm{C}$. We then determine the reaction rate and activation energy. We show that $\mathrm{C}$ thermal formation can occurs in the 50-70 K temperature range of a protostellar environment. Secondly, we report that a VUV photolysis of a pure $\mathrm{C}$ sample produces a glycine salt, methylammonium glycinate $\left[\mathrm{CH}_{3} \mathrm{NH}_{3}^{+}\right]\left[\mathrm{NH}_{2} \mathrm{CH}_{2} \mathrm{COO}^{-}\right]$noted G. We propose a scenario explaining how $\mathrm{C}$ and subsequently $\mathrm{G}$ can be synthesized in interstellar ices and precometary grains.

Conclusions. $\left[\mathrm{CH}_{3} \mathrm{NH}_{3}^{+}\right]\left[\mathrm{CH}_{3} \mathrm{NHCOO}^{-}\right]$could be readily formed and would act as a glycine salt precursor in protostellar environments dominated by thermal and UV processing. We propose a new pathway leading to a glycine salt, which is consistent with the detection of glycine and methylamine within the returned samples of comet 81P/Wild 2 from the Stardust mission.
\end{abstract}

Key words. astrochemistry - ISM: molecules - methods: laboratory

\section{Introduction}

Icy grains in the ISM play an important role in the chemistry of dense molecular clouds. They provide a surface upon which atoms and molecules can freeze out, forming icy mantles over the underlying silicates (O-rich) or carbonaceous (C-rich) grains. The current inventory of molecules within the icy grain mantles as inferred by ISO (Infrared Space Observatory), includes water $\left(\mathrm{H}_{2} \mathrm{O}\right)$, the dominant species, carbon monoxide $(\mathrm{CO})$, carbon dioxide $\left(\mathrm{CO}_{2}\right)$, methanol $\left(\mathrm{CH}_{3} \mathrm{OH}\right)$, ammonia $\left(\mathrm{NH}_{3}\right)$, and traces of other species (Dartois 2005).

These icy grains evolve from dense molecular clouds to planetary systems. During a molecular cloud collapse, a protostar surrounded by a gas and dust envelope is formed. This induces a warming up of icy grains and the reactions between frozen molecules lead to refractory compounds that remain on dust grains, while the most volatile compounds are delivered into the gas phase (hot corino, where the temperatures reach 100-200 K) (Cecarelli 2008). With time, the gas and dust envelope dissipates forming a protoplanetary disk, where the dust grains are distributed along the mid-plane. By means of yet unknown mechanisms, dust grains coagulate to form larger particles that eventually become planets, comets, and meteorites. During this evolution, organic material within grains experiences different types of chemical alteration (thermal processes, cosmic rays, and ultraviolet irradiations) depending on their location within star-forming regions.

Here, we are interested in the formation of the simplest amino acid, glycine $\left(\mathrm{NH}_{2} \mathrm{CH}_{2} \mathrm{COOH}\right)$, in protostellar environments. Numerous tentative detections of interstellar glycine have been reported but its identification has not yet been confirmed (Kuan et al. 2003; Snyder et al. 2005). Meteoritic glycine has been identified in both CM- and CI-type carbonaceous chondrites such as Murchison, Murray, Orgeuil, and Ivuna by using highly sensitive analytical techniques (Kvenvolden et al. 1970; Cronin \& Pizzarello 1997; Lawless 1972; Ehrenfreund et al. 2001a; Botta \& Bada 2002). In cometary coma, approximately 25 molecules have been detected by radio astronomy (Crovisier et al. 1998; Bockelée-Morvan et al. 2000; Despois 1999; Irvine et al. 2000), but not glycine (Ehrenfreund et al. 2002; Crovisier et al. 2004). Finally, within the returned samples of comet 81P/Wild 2 from the Stardust mission, traces of glycine and $\beta$-alanine have been detected as well as amines such as methylamine and ethylamine (Sandford et al. 2006; Glavin 2008). An open question is whether glycine can be synthesized in these environments.

Glycine can be formed in the laboratory by Strecker synthesis involving hydrogen cyanide $(\mathrm{HCN})$, ammonia $\left(\mathrm{NH}_{3}\right)$, and formaldehyde $\left(\mathrm{H}_{2} \mathrm{CO}\right)$. The Bucherer-Bergs synthesis is close to that of the Strecker synthesis with additional carbon dioxide 
$\left(\mathrm{CO}_{2}\right)$. These reactions can occur in laboratory VUV photolysis and thermal processes experiments performed on interstellar ice analogs (Munoz Caro et al. 2002; Bernstein et al. 2002; Elsila et al. 2007). After warming the irradiated ice to room temperature and hydrolyzing the residu obtained, glycine and other amino acids have been identified after GC-MS analysis. Other fruitful attempts to form interstellar glycine have been performed in the laboratory involving either ammonia $\left(\mathrm{NH}_{3}\right)$ and acetic acid $\left(\mathrm{CH}_{3} \mathrm{COOH}\right)$ or methylamine $\left(\mathrm{CH}_{3} \mathrm{NH}_{2}\right)$ and carbon dioxide $\left(\mathrm{CO}_{2}\right)$ mixtures, by electron bombardments at $10 \mathrm{~K}$ (Lafosse 2006; Holtom et al. 2005). Finally, the VUV irradiation of methylamine $\left(\mathrm{CH}_{3} \mathrm{NH}_{2}\right)$ and carbon dioxide $\left(\mathrm{CO}_{2}\right)$ adsorbed onto a water ice surface at $56 \mathrm{~K}$ has also been studied, using the analysis techniques of reactive ion scattering and low energy sputtering and resulting in the identification of the amino acid glycine or the relative isomers (Lee et al. 2009). No mechanism has yet been proposed and the authors do not take into account the thermal activity of their system at $56 \mathrm{~K}$.

Methylamine is an astrophysical important molecule, which has been detected by millimeter wave observations of the Sagittarius B2 and Orion A molecular clouds (Kaifu et al. 1974; Fourikis et al. 1974). Methylamine can be produced inside icy grains from the vacuum ultraviolet photolysis of other relatively abundant molecules, i.e., methane $\left(\mathrm{CH}_{4}\right)$ and ammonia $\left(\mathrm{NH}_{3}\right)$ (Garder \& McNesby 1980; Ogura et al. 1988), or methylium ion $\left(\mathrm{CH}_{3}^{+}\right)$and ammonia $\left(\mathrm{NH}_{3}\right)$ (Herbst 1985), or from a hydrogenation series based on the cyanide radical $(\mathrm{CN})$, hydrogen cyanide $(\mathrm{HCN})$, and methanimine $\left(\mathrm{H}_{2} \mathrm{C}=\mathrm{NH}\right)$ (Godfrey et al. 1973). One can also imagine that gas phase methylamine can simply stick onto icy grains. Methylamine is understood to be present on icy grains at concentrations of less than $1 \%$ relative to water. This is too low for its detections by remote infrared observations (Holtom et al. 2005).

In this paper, we provide experimental evidence of a glycine salt precursor formation from methylamine $\left(\mathrm{CH}_{3} \mathrm{NH}_{2}\right)$ and carbon dioxide $\left(\mathrm{CO}_{2}\right)$. A thermal reaction between both molecules in a water-dominated ice forms methylammonium methylcarbamate $\left[\mathrm{CH}_{3} \mathrm{NH}_{3}^{+}\right]\left[\mathrm{CH}_{3} \mathrm{NHCOO}^{-}\right]$. The photochemical behaviour of methylammonium methylcarbamate is studied independently. The optimal analysis conditions are achieved by the VUV irradiation at $10 \mathrm{~K}$ of a pure sample of methylammonium methylcarbamate (i.e., without water). We therefore show that by means of VUV irradiation, methylammonium methylcarbamate $\left[\mathrm{CH}_{3} \mathrm{NH}_{3}^{+}\right]\left[\mathrm{CH}_{3} \mathrm{NHCOO}^{-}\right]$is converted into a glycinate salt, methylammonium glycinate $\left[\mathrm{CH}_{3} \mathrm{NH}_{3}^{+}\right]\left[\mathrm{NH}_{2} \mathrm{CH}_{2} \mathrm{COO}^{-}\right]$. We propose a plausible scenario to explain the formation of glycine in protostellar environments and its possible introduction in comets or meteorites.

\section{Description of experimental methods}

The gases that we use include carbon dioxide $\left(\mathrm{CO}_{2}\right)$ (Linde, purity $99.9995 \%$ ), methylamine $\left(\mathrm{CH}_{3} \mathrm{NH}_{2}\right)$ (Air Liquide, purity $99.9995 \%$ ), and water that is distilled and purified by several freeze-thaw cycles within a primary vacuum. Gas mixtures are prepared in a single primary vacuum-pumped glass mixing ramp $\left(10^{-3} \mathrm{mbar}\right)$ at room temperature. The relative molecular abundances are obtained by standard manometric techniques using partial vapour pressure and from infrared spectra by estimating the column density of each component of the ices. These mixtures are introduced into a high vacuum chamber $\left(10^{-7}\right.$ mbar $)$ pumped by a turbomolecular pump, containing a rotating gold-plated metal surface cooled to $10 \mathrm{~K}$ by a model 21 CTI Cryogenics cold head. We use the following relation $N_{x}=\int \tau_{v, x} \mathrm{~d} v / A_{x}$, where $N_{x}$ is the number of absorbing molecules per $\mathrm{cm}^{2}$ (i.e., column density), $\int \tau_{v, x} \mathrm{~d} v$ is the integrated optical depth of an absorption line, and $A_{x}$ the relative band strength of the species $x$. The ratio of $N_{x}$ of the different mixtures allows us to derive more accurately the relative molecular abundances. We therefore integrate the infrared absorption features of the water stretching mode at $3279 \mathrm{~cm}^{-1}$ $\left(A_{\mathrm{H}_{2} \mathrm{O}}=2.0 \times 10^{-16} \mathrm{~cm} \mathrm{molecule}^{-1}\right)($ Oeberg et al. 2007), of carbon dioxide at $2340 \mathrm{~cm}^{-1}\left(A_{\mathrm{CO}_{2}}=7.1 \times 10^{-17} \mathrm{~cm} \mathrm{molecule}^{-1}\right)$ (Schutte \& Gerakines 1995) and of methylamine at $1156 \mathrm{~cm}^{-1}$ $\left(A_{\mathrm{CH}_{3} \mathrm{NH}_{2}}=1.5 \times 10^{-18} \mathrm{~cm}\right.$ molecule $\left.{ }^{-1}\right)($ Holtom et al. 2005).

A $\mathrm{H}_{2} \mathrm{O}: \mathrm{CO}_{2}: \mathrm{CH}_{3} \mathrm{NH}_{2}=10: 3: 0.5$ ice analog is deposited and then heated to $4 \mathrm{~K} \mathrm{~min}^{-1}$ to simulate the thermal effects of a star-forming region. The sample chemical evolution induced by thermal and photochemical processes is monitored by infrared spectroscopy and mass spectrometry. To determine the rate constant and activation energy of the thermal reaction, kinetic studies are performed at fixed temperature by means of the isolation method. For each isothermal experiment, the initial gas mixture is condensed at $10 \mathrm{~K}$, where the rate constant is too low to observe any reactivity between reactants. The warming of the ice to the desired temperature is then achieved rapidely to minimize the thermal effects between the temperature of deposition and the final temperature reached.

Infrared spectra are acquired by a FTIR spectrometer (NICOLET Magna 750) and recorded in the reflection mode in the 4000-650 $\mathrm{cm}^{-1}$ range. A typical spectrum has $1 \mathrm{~cm}^{-1}$ resolution and is averaged over 100 interferograms. A RGA quadrupole mass spectrometer (MKS Microvision-IP plus) is used to obtain information about the molecules delivered in the gaseous phase. The mass spectra are recorded between 1 and $80 \mathrm{amu}$ (atomic mass units). The ionization source is defined to have a $70 \mathrm{eV}$ electronic impact energy.

Ultraviolet photolysis experiments are performed using a microwave-discharge hydrogen flow lamp (Opthos instruments). The UV photon flux reaching the sample is $2 \times 10^{13}$ photons $\mathrm{cm}^{-2} \mathrm{~s}^{-1}$. One hour of UV irradiation in the laboratory simulates the processing of interstellar ices for $\sim 2 \times 10^{6}$ years in a dense cloud (UV flux about $1 \times 10^{3}$ photons $\mathrm{cm}^{-2} \mathrm{~s}^{-1}$ ) (Prasad \& Tarafdar 1983; Gredel et al. 1989). The lamp is mounted directly onto the sample chamber and the UV photons are transmitted through a $\mathrm{MgF}_{2}$ window (transparent at the radiation range $\lambda>110 \mathrm{~nm})$.

Pure methylammonium methylcarbamate used for the characterization and ultraviolet photolysis is thermally obtained from a $\mathrm{CO}_{2}: \mathrm{CH}_{3} \mathrm{NH}_{2}=1: 5$ binary ice mixture deposited at $10 \mathrm{~K}$ (Bossa et al. 2008a). To avoid the photoproducts of the initial mixture, the sample is purified by warming and after the sublimation of the remaining carbon dioxide and methylamine at $200 \mathrm{~K}$, pure methylammonium methylcarbamate is retained on the deposition surface. The sample is finally cooled to $10 \mathrm{~K}$ before being vacuum ultraviolet photolyzed.

To characterize the photochemical products formed, we record the infrared spectra of pure methylcarbamic acid $\left(\mathrm{CH}_{3} \mathrm{NHCOOH}\right)$, following the procedure described previously (Bossa et al. 2008a) and methylammonium glycinate $\left[\mathrm{CH}_{3} \mathrm{NH}_{3}^{+}\right]\left[\mathrm{NH}_{2} \mathrm{CH}_{2} \mathrm{COO}^{-}\right]$according to the procedure described below.

Methylammonium glycinate is obtained by warming a methylamine and neutral glycine binary ice mixture. Glycine (Sigma-Aldrich, purity 99\%) is warmed from a glass tube mounted directly onto the sample chamber and sublimes in its non-ionic form $\left(\mathrm{NH}_{2} \mathrm{CH}_{2} \mathrm{COOH}\right)$. It can then be channelled by 


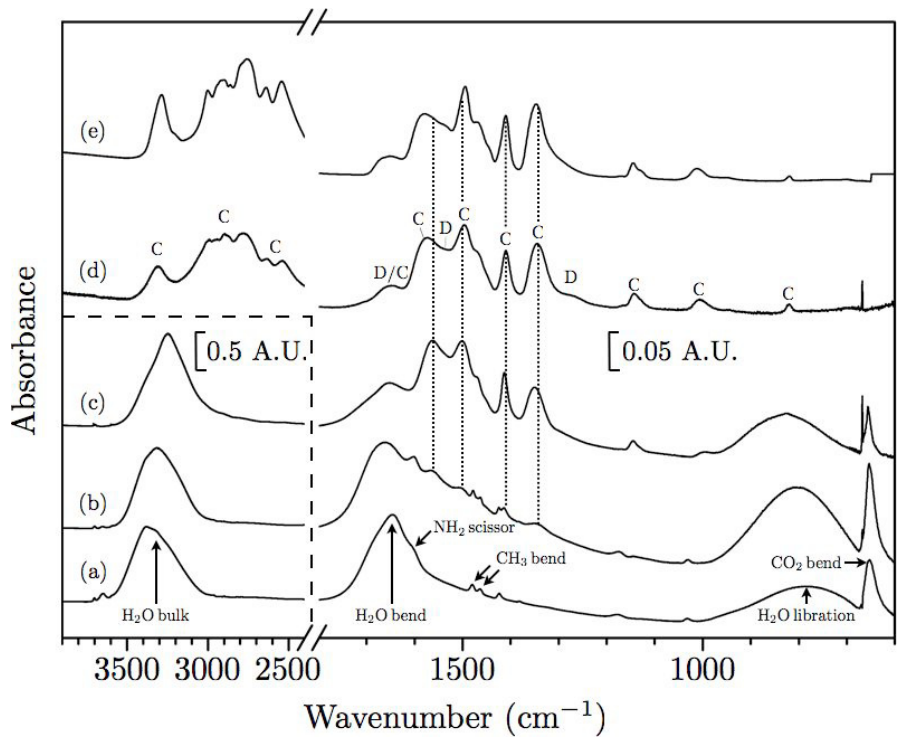

Fig. 1. Formation of methylammonium methylcarbamate $\left[\mathrm{CH}_{3} \mathrm{NH}_{3}^{+}\right]$ $\left[\mathrm{CH}_{3} \mathrm{NHCOO}^{-}\right]$, from the thermal activation of carbon dioxide $\left(\mathrm{CO}_{2}\right)$ and methylamine $\left(\mathrm{CH}_{3} \mathrm{NH}_{2}\right)$ in a water-dominated ice. a) Infrared spectra of a $\mathrm{H}_{2} \mathrm{O}: \mathrm{CO}_{2}: \mathrm{CH}_{3} \mathrm{NH}_{2}=10: 3: 0.5$ ice film deposited at $10 \mathrm{~K}$ then recorded, b) after heating to $120 \mathrm{~K}$, c) before water desorption at $180 \mathrm{~K}$, d) after the complete desorption of water ice at $200 \mathrm{~K}$, and e) infrared spectra of pure methylammonium methylcarbamate at $10 \mathrm{~K}$ obtained from a thermal process of a $\mathrm{CH}_{3} \mathrm{NH}_{2}: \mathrm{CO}_{2}=5: 1$ ratio. The $\mathrm{C}$ abbreviation refers to methylammonium methylcarbamate and $\mathrm{D}$ refers to the dimer form of methylcarbamic acid (Bossa et al. 2008a).

a methylamine carrier gas. After condensing the gas mixture at $10 \mathrm{~K}$, the sample is warmed to $150 \mathrm{~K}$. After sublimation of the remaining methylamine, pure methylammonium glycinate is formed from an acid-base reaction type. Subsequently, the methylammonium glycinate sample is cooled to $10 \mathrm{~K}$ before identification. Comparisons are made with the ATR spectrum of sodium glycinate $\left[\mathrm{Na}^{+}, \mathrm{NH}_{2} \mathrm{CH}_{2} \mathrm{COO}^{-}\right]$(Sigma-Aldrich, purity $99 \%$ ) to facilitate its characterization.

\section{Results}

\subsection{Formation of methylammonium methylcarbamate (C) in a water-dominated ice}

Carbamates are chemical products with the general structure $\left[\mathrm{R}-\mathrm{NHCO}_{2}^{-}\right]$. In aqueous solution, carbon dioxide $\left(\mathrm{CO}_{2}\right)$ and primary amines $\left(\mathrm{R}-\mathrm{NH}_{2}\right)$ yield alkylammonium alkylcarbamates $\left[\mathrm{R}_{-} \mathrm{NH}_{3}^{+}\right]\left[\mathrm{R}-\mathrm{NHCO}_{2}^{-}\right]$(DellAmico et al. 2003) according to the reaction described below:

$\mathrm{CO}_{2}+2 \mathrm{R}-\mathrm{NH}_{2} \rightarrow\left[\mathrm{R}-\mathrm{NH}_{3}^{+}\right]\left[\mathrm{R}-\mathrm{NHCO}_{2}^{-}\right]$.

We have shown that the simplest carbamate $\left[\mathrm{NH}_{2} \mathrm{CO}_{2}{ }^{-}\right]$could be thermally produced from icy grains containing $\mathrm{NH}_{3}$ and $\mathrm{CO}_{2}$ (Bossa et al. 2008b). From a $\mathrm{CO}_{2}: \mathrm{CH}_{3} \mathrm{NH}_{2}=1: 5$ binary ice mixture, pure methylammonium methylcarbamate $\left[\mathrm{CH}_{3} \mathrm{NH}_{3}^{+}\right]\left[\mathrm{CH}_{3} \mathrm{NHCOO}^{-}\right]$is thermally produced (Bossa et al. 2008a). The infrared spectrum of $\mathrm{C}$ is presented in Fig. 1e, and the vibrational bands are reported in Table 1. However, a $\mathrm{CO}_{2}: \mathrm{CH}_{3} \mathrm{NH}_{2}=1: 5$ mixture is not a realistic astrophysical ice because we expect $\mathrm{CO}_{2}$ to be in excess compared to $\mathrm{CH}_{3} \mathrm{NH}_{2}$. Futhermore, both molecules should be diluted in a water-dominated environment. We report (Fig. 1) the results of the thermal evolution of a $\mathrm{H}_{2} \mathrm{O}: \mathrm{CO}_{2}: \mathrm{CH}_{3} \mathrm{NH}_{2}=10: 3: 0.5$ ice

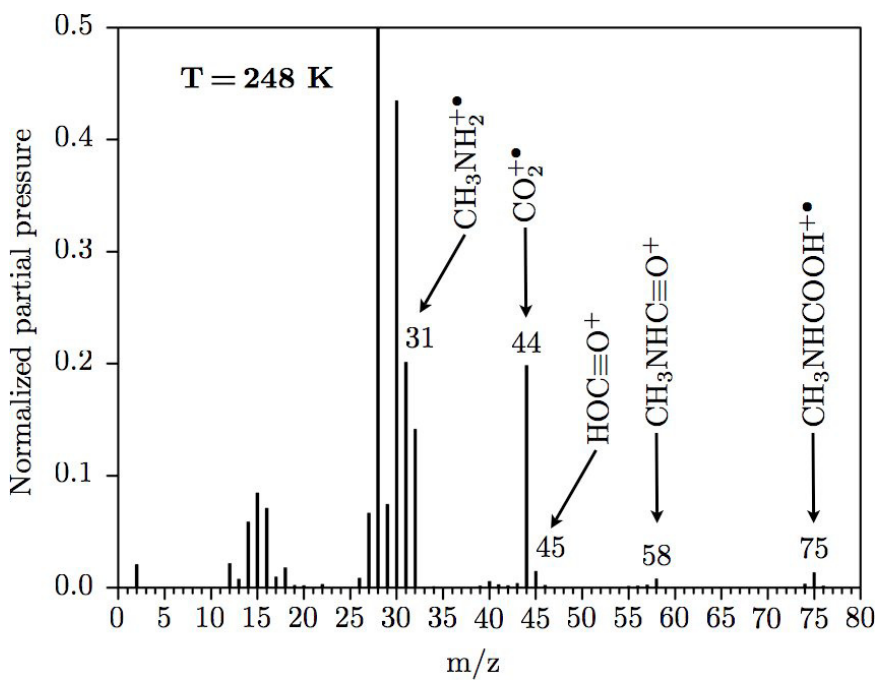

Fig. 2. Electronic impact mass spectra $(70 \mathrm{eV})$ during the methylammonium methylcarbamate $\left[\mathrm{CH}_{3} \mathrm{NH}_{3}^{+}\right]\left[\mathrm{CH}_{3} \mathrm{NHCOO}^{-}\right]$decomposition at $248 \mathrm{~K}$.

analog mixture deposited at $10 \mathrm{~K}$, which is a more astrophysicaly relevant ice.

Although introduced at less than $5 \%$ relative to water in the mixture, $\mathrm{CH}_{3} \mathrm{NH}_{2}$ features are hardly observable because of the weakness of the band strengths measured for this molecule. Nevertheless, no reaction is observed at $10 \mathrm{~K}$ (Fig. 1a). At temperature above $100 \mathrm{~K}$ (Fig. 1b), new infrared absorption bands appear and can be assigned to a new and dominant species. We deduce that this species is $\mathrm{C}$ by comparison with its relative spectrum in Fig. 1e. After the complete desorption of $\mathrm{H}_{2} \mathrm{O}$ and $\mathrm{CO}_{2}$ above $180 \mathrm{~K}$ (Figs. 1c and d), a thin layer consisting mainly of C remains on the gold plate until it fully decomposes above $240 \mathrm{~K}$. The $\mathrm{C}$ decomposition is observed by mass spectrometry during the warming of the $\mathrm{C}$ sample. The recorded mass spectrum at $248 \mathrm{~K}$ (Fig. 2) displays the presence of peaks corresponding to the $\mathrm{CH}_{3} \mathrm{NHCOOH}$ molecular ion at $\mathrm{m} / \mathrm{z}=75, \mathrm{~m} / \mathrm{z}=58$ $\left(\mathrm{CH}_{3} \mathrm{NHCO}^{+}\right)$and $\mathrm{m} / z=45\left(\mathrm{COOH}^{+}\right)$. The $\mathrm{C}$ decomposition occurs after the complete desorption of water, and $\mathrm{C}$ is therefore more refractory than the most volatile molecules found into icy grains.

\subsection{Determination of the rate constants $(k)$ and the activation energy $\left(E_{a}\right)$ of the methylammonium methylcarbamate thermal formation in a water-dominated ice}

The rate constants $k$ for the thermal reaction described in Eq. (2) in a water-dominated ice at different temperatures are investigated in the $80-110 \mathrm{~K}$ temperature range:

$\mathrm{CO}_{2}+2 \mathrm{CH}_{3} \mathrm{NH}_{2} \stackrel{k}{\longrightarrow}\left[\mathrm{CH}_{3} \mathrm{NH}_{3}^{+}\right]\left[\mathrm{CH}_{3} \mathrm{NHCOO}^{-}\right]$.

We follow the time evolution of carbon dioxide infrared absorption band at $2340 \mathrm{~cm}^{-1}$ for specific temperatures. The determination of the rate law is realized using the isolation method, where methylamine is in excess within the mixture. We observe that the integrated absorption band of carbon dioxide $\left(A_{\mathrm{CO}_{2}}\right)$ undergoes a first order partial decay. The kinetic law can therefore be written as

$-\mathrm{d} A_{\mathrm{CO}_{2}} / \mathrm{d} t=k^{\prime} \times A_{\mathrm{CO}_{2}}$

$k^{\prime}=k \times\left(X_{\mathrm{CH}_{3} \mathrm{NH}_{2}}\right)_{0}^{\alpha}$, 
Table 1. Infrared band position $\left(\mathrm{cm}^{-1}\right)$ and assignment of pure methylammonium methylcarbamate $(\mathrm{C})$ at $10 \mathrm{~K}$, pure methylammonium glycinate (G) at $10 \mathrm{~K}$, pure methylamine at $10 \mathrm{~K}$ and pure methylcarbamic acid.

\begin{tabular}{|c|c|c|c|c|}
\hline "Vibration & $\begin{array}{c}{\left[\mathrm{CH}_{3} \mathrm{NH}_{3}^{+}\right]\left[\mathrm{CH}_{3} \mathrm{NHCOO}^{-}\right]} \\
(\mathrm{C})^{1}\end{array}$ & $\begin{array}{c}{\left[\mathrm{CH}_{3} \mathrm{NH}_{3}^{+}\right]\left[\mathrm{NH}_{2} \mathrm{CH}_{2} \mathrm{COO}^{-}\right]} \\
(\mathrm{G})^{2}\end{array}$ & $\begin{array}{c}\mathrm{CH}_{3} \mathrm{NH}_{2} \\
\text { Methylamine }\end{array}$ & $\begin{array}{c}\mathrm{CH}_{3} \mathrm{NHCOOH} \\
\text { Methylcarbamic acid }\end{array}$ \\
\hline$v \mathrm{NH} \mathrm{H}$ bonding & $\cdots$ & $\cdots$ & 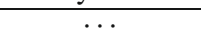 & 3367 \\
\hline$v_{\mathrm{as}} \mathrm{NH}_{2}$ & $\ldots$ & 3340 & 3343 & $\ldots$ \\
\hline$v \mathrm{NH}$ & 3287 & $\ldots$ & $\ldots$ & $\ldots$ \\
\hline$v_{\mathrm{s}} \mathrm{NH}_{2}$ & $\ldots$ & 3285 & 3282 & $\ldots$ \\
\hline $\mathrm{H}$ bonding & .. & 3210 & 3182 & \\
\hline$v \mathrm{OH}$ & $\ldots$ & $\ldots$ & $\ldots$ & $3062 / 2985$ \\
\hline$v_{\mathrm{s}} \mathrm{NH}_{3} \mathrm{CH}_{3} \mathrm{NH}_{3}^{+}$ & 3002 & 3005 & $\ldots$ & $\cdots$ \\
\hline Combination $\mathrm{CH}_{3} \mathrm{NH}_{3}^{+}$ & 2642 & 2651 & $\ldots$ & $\ldots$ \\
\hline Combination $\mathrm{CH}_{3} \mathrm{NH}_{3}^{+}$ & 2544 & 2549 & $\ldots$ & $\ldots$ \\
\hline$v \mathrm{C}=\mathrm{O}$ & $\ldots$ & $\ldots$ & $\ldots$ & $1679 / 1672$ \\
\hline$\delta_{\text {as }} \mathrm{NH}_{3} \mathrm{CH}_{3} \mathrm{NH}_{3}^{+}$ & 1652 & 1655 & $\ldots$ & $\cdots$ \\
\hline$\delta \mathrm{NH}_{2}$ & $\ldots$ & 1635 & 1615 & $\ldots$ \\
\hline$v \mathrm{CN}+\delta \mathrm{NH}$ & $\ldots$ & $\ldots$ & $\ldots$ & $1574 / 1533$ \\
\hline$v_{\mathrm{as}} \mathrm{COO}^{-}$ & 1578 & 1565 & $\cdots$ & $\cdots$ \\
\hline$\delta \mathrm{NH}$ & 1494 & $\ldots$ & $\ldots$ & $\cdots$ \\
\hline$\delta_{\text {as }} \mathrm{CH}_{3} \mathrm{CH}_{3} \mathrm{NH}_{3}^{+}$ & 1471 & 1471 & $\ldots$ & $\ldots$ \\
\hline$\delta_{\mathrm{d}} \mathrm{CH}_{3}$ & 1347 & $\ldots$ & $1478 / 1455$ & $1441 / 1420$ \\
\hline$\delta \mathrm{CH}_{2}$ & $\ldots$ & 1442 & .. & $\ldots$ \\
\hline$v_{\mathrm{s}} \mathrm{COO}^{-}$ & 1410 & 1403 & $\ldots$ & $\ldots$ \\
\hline$\delta \mathrm{OH}$ & .. & $\ldots$ & $\ldots$ & 1396 \\
\hline tw $\mathrm{NH}_{2}$ & $\ldots$ & 1330 & 1339 & $\ldots$ \\
\hline tw $\mathrm{CH}_{2}$ & $\cdots$ & 1310 & $\cdots$ & $\ldots$ \\
\hline$\delta \mathrm{OH}+v \mathrm{C}-\mathrm{O}$ & $\ldots$ & $\ldots$ & $\ldots$ & $1315 / 1263$ \\
\hline
\end{tabular}

References. (1) (Waldron 1953; Cabana \& Sandorfy 1962; Castellucci 1974; Bossa et al. 2008a); (2) (Rosado et al. 1998); (3) (Bossa et al. 2008a; Durig et al. 1968); (4) (Bossa et al. 2008a).

Comments: Vibration mode: stretching $(v)$, bending $(\delta)$ and twisting (tw). Indication: asymmetric (as), symmetric (s) and degenerated (d).

where $\left(X_{\mathrm{CH}_{3} \mathrm{NH}_{2}}\right)_{0}^{\alpha}$ in Eq. (4) is defined as the molar fraction of methylamine in the initial mixture. This value is obtained from the column density of methylamine, carbon dioxide, and water. The solution of Eq. (3) leads to Eq. (5), from which the bestfit solution of the temporal profiles yield a set of $k^{\prime}$ values for specific temperatures, as listed in Table 2.

$\left(A_{\mathrm{CO}_{2}}\right)_{t}=\left(A_{\mathrm{CO}_{2}}\right)_{0} \times \exp \left(-k^{\prime} \times t\right)$.

The partial order relative to the molar fraction of methylamine, $\alpha$ is obtained by means of $\ln \left(k^{\prime}\right)=\alpha \times \ln \left[\left(X_{\mathrm{CH}_{3} \mathrm{NH}_{2}}\right)_{0}\right]+\ln (k)$, by plotting $\ln \left(k^{\prime}\right)$ versus $\ln \left[\left(X_{\mathrm{CH}_{3} \mathrm{NH}_{2}}\right)_{0}\right]$. This was achieved by a set of experiments performed at $102 \mathrm{~K}$ by changing in each experiment the molar fraction of methylamine. The $\alpha$ value obtained is about 0.46 . We therefore deduce from Eq. (4) the different $k$ values for each specific temperature (listed in Table 2). From the Arrhenius law given in Eq. (6), we determine the activation energy of the methylammonium methylcarbamate thermal formation as displayed in Fig. $3, E_{a}=3.7 \pm 0.5 \mathrm{~kJ} \mathrm{~mol}^{-1}$ and the frequency factor, $A=1.1 \mathrm{~min}^{-1}$ :

$\ln (k)=\ln (A)-E_{a} / R T$.

Both values are useful to estimate the set of $k$ values in the temperature range of protostellar environments: $k(T)=1.1 \times$ $\exp (-3700 / R T)$. We include the $k(T)$ expressions in Eq. (4) and we obtain $k^{\prime}=1.1 \times \exp (-3700 / R T) \times\left(X_{\mathrm{CH}_{3} \mathrm{NH}_{2} \text {-ices }}\right)^{\alpha}$. We consider that on interstellar icy grains, the upper limit to the molar fraction of methylamine $\left(X_{\mathrm{CH}_{3} \mathrm{NH}_{2} \text {-ices }}\right)$ equals $1 \%$ relative to water (Holtom et al. 2005). From the relation $t_{1 / 2}(T)=\ln (2) / k^{\prime}$, we deduce, by extrapolation in the $50-100 \mathrm{~K}$ temperature range, the carbon dioxide half-time onto interstellar icy grains involved in the thermal reaction with methylamine to yield methylammonium methylcarbamate in a water-dominated ice.

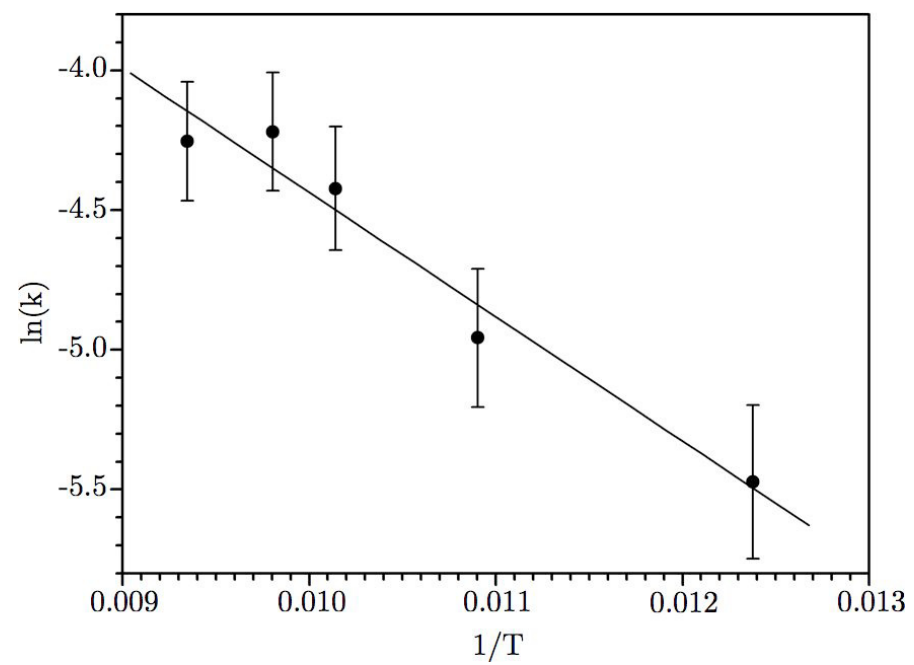

Fig. 3. Linear fit to the Arrhenius plot of $\ln (k)$ vs. $1 / T$ for the methylammonium methylcarbamate thermal formation in the 80-110 K temperature range. The fitted slope infers $-E_{a} / R\left(E_{a}=3.7 \pm 0.5 \mathrm{~kJ} \mathrm{~mol}^{-1}\right)$ and the intercept at $1 / T=0$ gives $A=1.1 \mathrm{~min}^{-1}$.

The set of $\mathrm{CO}_{2}$ half-times onto interstellar icy grains are listed in Table 3. Table 3 shows the comparison between these values and the residence times of $\mathrm{CO}_{2}$ on water ice as a function of the corresponding temperature. This comparison is helpful for determining the possibility of the methylammonium methylcarbamate thermal formation on interstellar icy grains located in protostellar environments during a typical time of $10^{6}-10^{7}$ years. 
Table 2. Reaction rate $\mathrm{k}$ measured for methylammonium methylcarbamate formation at a fixed temperature.

\begin{tabular}{lllll}
\hline \hline $\begin{array}{l}\text { Temperature } \\
(\mathrm{K})\end{array}$ & $\begin{array}{l}\text { Ice mixtures } \\
\mathrm{CO}_{2}: \mathrm{CH}_{3} \mathrm{NH}_{2}: \mathrm{H}_{2} \mathrm{O}\end{array}$ & $\begin{array}{l}\left(\mathrm{X}_{\left.\mathrm{CH}_{3} \mathrm{NH}_{2}\right)_{0}}\right. \\
\text { molar fraction }\end{array}$ & $\begin{array}{l}k^{\prime} \\
\left(\mathrm{min}^{-1}\right)\end{array}$ & $\begin{array}{l}k \\
\left(\mathrm{~min}^{-1}\right)\end{array}$ \\
\hline 80.8 & $3.9: 13: 10$ & 0.48 & $(3.0 \pm 0.3) \times 10^{-3}$ & $4.2 \times 10^{-3}$ \\
91.7 & $1.5: 5.2: 10$ & 0.31 & $(4.1 \pm 0.7) \times 10^{-3}$ & $7.0 \times 10^{-3}$ \\
98.6 & $1.5: 5.9: 10$ & 0.34 & $(7.3 \pm 0.7) \times 10^{-3}$ & $1.2 \times 10^{-2}$ \\
102 & $2.0: 6.0: 10$ & 0.33 & $(8.8 \pm 0.9) \times 10^{-3}$ & $1.5 \times 10^{-2}$ \\
107 & $1.0: 4.9: 10$ & 0.31 & $(8.3 \pm 1.2) \times 10^{-3}$ & $1.4 \times 10^{-2}$ \\
\hline
\end{tabular}

Table 3. Comparison between the calculated $\mathrm{CO}_{2}$ half-times involved in the methylammonium methylcarbamate $(\mathrm{C})$ thermal formation and the calculated residence times of $\mathrm{CO}_{2}$ on water ice at different temperatures.

\begin{tabular}{lll}
\hline \hline $\begin{array}{l}\text { Temperature } \\
(\mathrm{K})\end{array}$ & $\begin{array}{l}\mathrm{CO}_{2} \text { half-times to } \\
\mathrm{C} \text { formation }(\mathrm{yr})\end{array}$ & $\begin{array}{l}\mathrm{CO}_{2} \text { residence times } \\
\text { on water ice }\end{array}(\mathrm{yr})$ \\
\hline 50 & $8 \times 10^{-2}$ & $7 \times 10^{4}$ \\
60 & $2 \times 10^{-2}$ & $5 \times 10^{0}$ \\
70 & $6 \times 10^{-3}$ & $6 \times 10^{-3}$ \\
80 & $3 \times 10^{-3}$ & $4 \times 10^{-5}$ \\
90 & $2 \times 10^{-3}$ & $7 \times 10^{-7}$ \\
100 & $9 \times 10^{-4}$ & $3 \times 10^{-8}$ \\
\hline
\end{tabular}

Reference. (1) Sandford \& Allamandola (1993).

\subsection{Photolysis of pure methylammonium methylcarbamate (C) at low temperature}

The photolysis of methylammonium methylcarbamate is achieved independently of its thermal formation in waterdominated ice. Pure methylammonium methylcarbamate photolysis at $10 \mathrm{~K}$ gives rise to new infrared absorption bands relative to newly formed species. In Fig. 4e, we display the difference spectrum recorded between $240 \mathrm{~min}$ of VUV photolysis and before any photolysis, where the remaining methylammonium methylcarbamate contributions have been subtracted. Hence, Fig. 4e depicts only the infrared features relative to the photochemical products. We identify methylcarbamic acid $\left(\mathrm{CH}_{3} \mathrm{NHCOOH}\right)$ (Fig. 4a) and methylamine $\left(\mathrm{CH}_{3} \mathrm{NH}_{2}\right)$ (Fig. 4b) by comparing the infrared spectra of the respective pure samples (Bossa et al. 2008a; Durig et al. 1968). The formation of both products is consistent with a proton transfer induced by ultraviolet photons from methylammonium cation $\left[\mathrm{CH}_{3} \mathrm{NH}_{3}^{+}\right]$to methylcarbamate anion $\left[\mathrm{CH}_{3} \mathrm{NHCOO}^{-}\right]$as described below:

$\left[\mathrm{CH}_{3} \mathrm{NH}_{3}^{+}\right]\left[\mathrm{CH}_{3} \mathrm{NHCOO}^{-}\right] \stackrel{h v}{\longrightarrow} \mathrm{CH}_{3} \mathrm{NH}_{2}+\mathrm{CH}_{3} \mathrm{NHCOOH}$.

The infrared spectra corresponding to both products cannot explain the difference spectrum of the irradiated sample. Some features, such as the most intense band at $1565 \mathrm{~cm}^{-1}$ are not yet assigned and suggest the formation of a third species.

Glycine can exist in different forms depending on the environment (acid, neutral/zwitterionic, or basic). A comparison with the spectra of glycine, in either a neutral $\left(\mathrm{NH}_{2} \mathrm{CH}_{2} \mathrm{COOH}\right)$ or a zwitterionic form $\left(\mathrm{NH}_{3}^{+} \mathrm{CH}_{2} \mathrm{COO}^{-}\right)$, is indecisive (Gomez-Zavaglia \& Fausto 2003; Rosado et al. 1998). In a basic environment, glycine exits as a glycinate salt $\left[\mathrm{NH}_{2} \mathrm{CH}_{2} \mathrm{COO}^{-}\right]$. The infrared spectrum of commercial sodium glycinate $\left[\mathrm{Na}^{+}, \mathrm{NH}_{2} \mathrm{CH}_{2} \mathrm{COO}^{-}\right]$(Fig. 5a) is close to the unknown infrared features. Closer agreement is obtained with the infrared spectrum of methylammonium glycinate $\left[\mathrm{CH}_{3} \mathrm{NH}_{3}^{+}\right]\left[\mathrm{NH}_{2} \mathrm{CH}_{2} \mathrm{COO}^{-}\right]$(Figs. $4 \mathrm{c}$ and $5 \mathrm{~b}$ ). The infrared absorption bands of methylammonium glycinate (noted

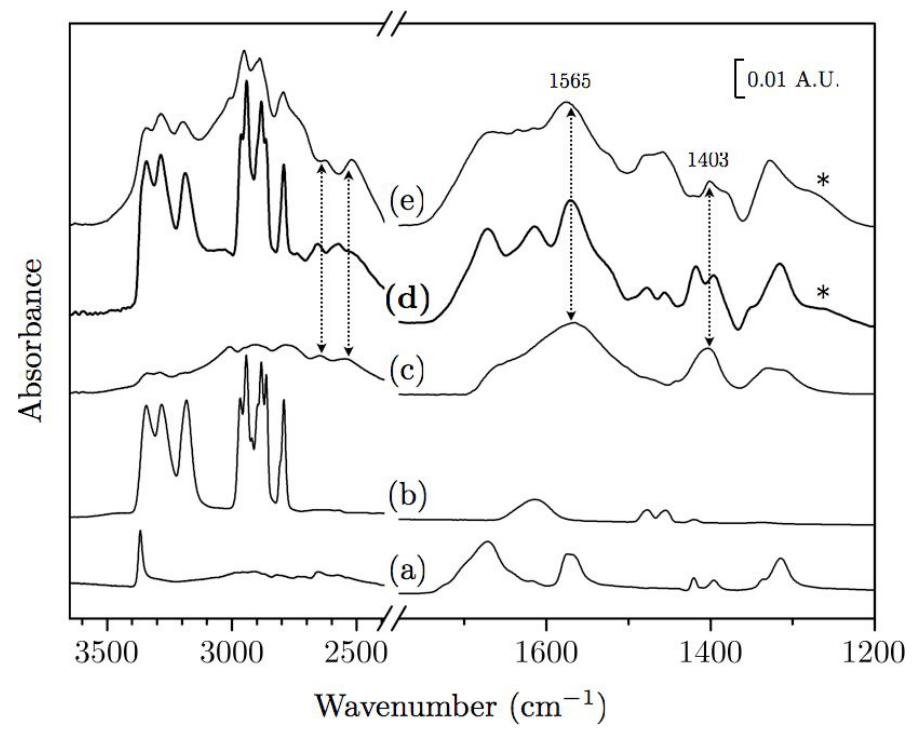

Fig. 4. Formation of methylammonium glycinate $\left[\mathrm{CH}_{3} \mathrm{NH}_{3}^{+}\right]$ $\left[\mathrm{NH}_{2} \mathrm{CH}_{2} \mathrm{COO}^{-}\right]$from the vacuum ultraviolet photolysis of pure methylammonium methylcarbamate $\left[\mathrm{CH}_{3} \mathrm{NH}_{3}^{+}\right]\left[\mathrm{CH}_{3} \mathrm{NHCOO}^{-}\right]$at low temperature $(10 \mathrm{~K})$. Comparison between the infrared spectra of a) pure methylcarbamic acid $\left(\mathrm{CH}_{3} \mathrm{NHCOOH}\right)$; b) pure methylamine $\left(\mathrm{CH}_{3} \mathrm{NH}_{2}\right)$ at $10 \mathrm{~K}$; c) pure methylammonium glycinate $\left[\mathrm{CH}_{3} \mathrm{NH}_{3}^{+}\right]\left[\mathrm{NH}_{2} \mathrm{CH}_{2} \mathrm{COO}^{-}\right]$at $10 \mathrm{~K}$; d) sum of spectra a) $\left.+\mathbf{b}\right)+\mathbf{c}$ ) and e) difference spectrum after VUV photolysis (240 min) minus before VUV photolysis with the remaining methylammonium methylcarbamate (C) contributions subtracted. The minor discrepancy between e) and d) spectra can be explained by environment effects that are not taken into account in the sum spectra. The infrared absorption feature $(*)$ is relative to the dimer form of methylcarbamic acid (Bossa et al. 2008a) and its pure infrared spectra has been omitted for clarity.

G) are listed with their assignments in Table 1. These assignments are confirmed by comparing the infrared spectrum of the sodium glycinate (Fig. 5a) with that of methylammonium glycinate (Fig. 5b). The main differences with the sodium glycinate spectrum come from the methylammonium $\left[\mathrm{CH}_{3} \mathrm{NH}_{3}^{+}\right]$counterion, which adds several features in the infrared spectrum.

The detection of $\mathrm{G}$ from the pure $\mathrm{C}$ photolysis is then straightforward, mainly by means of the methylammonium $\left[\mathrm{CH}_{3} \mathrm{NH}_{3}^{+}\right]$vibrational bands (Waldron 1953; Cabana \& Sandorfy 1962; Castellucci 1974; Bossa et al. 2008a) located between 3200 and $2500 \mathrm{~cm}^{-1}$ as well as the most intense $\mathrm{G}$ contributions corresponding to the $\mathrm{CO}_{2}^{-}$asymmetric and symmetric modes at $1565 \mathrm{~cm}^{-1}$ and $1403 \mathrm{~cm}^{-1}$ (Figs. 5b and c). A simple addition of the spectra corresponding to methylcarbamic acid (Fig. 4a), methylamine (Fig. 4b), and methylammonium glycinate (Fig. 4c) reproduces rather faithfully the photochemical product infrared spectrum (Figs. $4 \mathrm{~d}$ and e). The minor discrepancy between both spectra can be explained by the environment effects that are not taken into account in the sum spectrum 


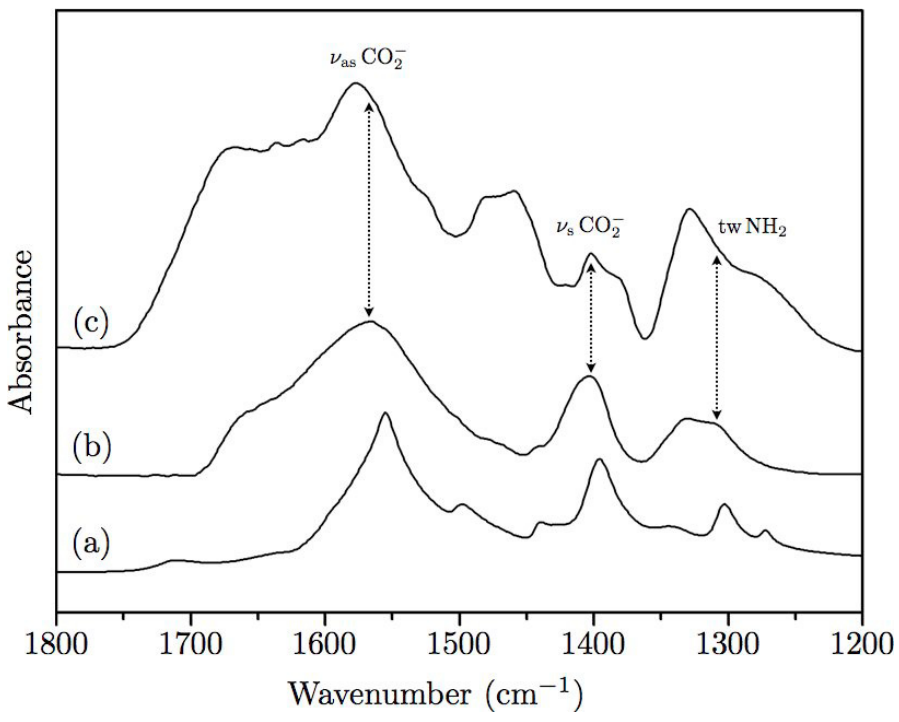

Fig. 5. Comparison between the infrared spectra of a) ATR spectrum of the glycine sodium salt $\left[\mathrm{Na}^{+}, \mathrm{NH}_{2} \mathrm{CH}_{2} \mathrm{COO}^{-}\right]$at room temperature; b) methylammonium glycinate $\left[\mathrm{CH}_{3} \mathrm{NH}_{3}^{+}\right]\left[\mathrm{NH}_{2} \mathrm{CH}_{2} \mathrm{COO}^{-}\right]$at $10 \mathrm{~K}$; c) difference spectrum after VUV photolysis $(240 \mathrm{~min})$ minus before VUV photolysis with the remaining methylammonium methylcarbamate (C) contributions subtracted. Comments: Vibration mode: stretching $(v)$ and twisting (tw). Indication: asymmetric (as) and symmetric (s).

(Fig. 4d) and are known to affect both the band profiles and the band strengths.

\subsection{Estimation of methylammonium glycinate (G) produced by pure methylammonium methylcarbamate $(C)$ during the VUV photolysis}

We quantify the methylammonium glycinate production by the VUV irradiation of pure methylammonium methylcarbamate. This is achieved by calculating the total column density of $\mathrm{G}$ formed and $\mathrm{C}$ consumed. The quantitative analysis of $\mathrm{G}$ formed is derived from its infrared spectrum (Fig. 4c) adjusted to achieve the best fit to the difference spectrum (Fig. 4e). The column density of $\mathrm{G}$ formed is measured from the optical depth located at $1403 \mathrm{~cm}^{-1}$, corresponding to the $v_{\mathrm{S}} \mathrm{CO}_{2}^{-}$fundamental mode but its band strength is unknown. This value is determined by the thermal conversion of a pure sample of methylammonium glycinate into zwitterionic glycine $\left(\mathrm{NH}_{3}^{+} \mathrm{CH}_{2} \mathrm{COO}^{-}\right)$, noted $Z$, represented by

$$
\left[\mathrm{CH}_{3} \mathrm{NH}_{3}^{+}\right]\left[\mathrm{NH}_{2} \mathrm{CH}_{2} \mathrm{COO}^{-}\right] \stackrel{\Delta}{\longrightarrow} \mathrm{CH}_{3} \mathrm{NH}_{2}+\mathrm{NH}_{3}^{+} \mathrm{CH}_{2} \mathrm{COO}^{-} \text {. }
$$

We choose a $Z$ band at $1414 \mathrm{~cm}^{-1}$ without any overlap to determine its band strength $\left(A_{Z}\right)$. Preparing a calibrated $\mathrm{KBr}$ pellet of commercial $Z$, we found a $A_{Z}$ value of $4.5 \times 10^{-18} \mathrm{~cm}$ molecule ${ }^{-1}$ for this band. From the equation, $A_{\mathrm{G}}=\mathrm{A}_{Z} \times\left(\int \tau_{v, \mathrm{G}} \mathrm{d} v / \int \tau_{v, Z} \mathrm{~d} v\right)$, we deduce the infrared band strength of $\mathrm{G}$ located at $1403 \mathrm{~cm}^{-1}$ $\left(A_{\mathrm{G}}=2.7 \times 10^{-18} \mathrm{~cm}\right.$ molecule $\left.{ }^{-1}\right)$. The column density of $\mathrm{C}$ consumed is measured from its optical depth over two characteristic absorption bands: $1410 \mathrm{~cm}^{-1}\left(0.5 \times 10^{-17} \mathrm{~cm} \mathrm{molecule}^{-1}\right)$ and $819 \mathrm{~cm}^{-1}\left(0.3 \times 10^{-18} \mathrm{~cm} \mathrm{molecule}^{-1}\right)$ (Bossa et al. 2008a). We provide a rough quantitative estimation of the branching ratio, $\mathrm{G}_{\text {(producted) }} / \mathrm{C}_{\text {(totalconsumed) }} \sim 65 \%$. This result indicates that the isomerization induced by UV photons is more favorable than the proton transfert process (Eq. (7)).

After irradiation (240 min), 50\% of the $\mathrm{C}$ is consumed by the photolysis. From these measurements, we can obtain a rough quantitative estimation of the photolysis yield of glycinate produced to be about $32 \%$. Nevertheless, the same irradiation experiment with methylammonium methylcarbamate diluted in water should lower this photolysis yield.

\section{Discussion}

During their lifetime in a protostellar environment $\left(10^{6}-\right.$ $10^{7}$ years), interstellar ices can be submitted to both thermal and UV photolysis processing that change the grain chemical composition.

Our investigations show that a glycine isomer salt, methylammonium methylcarbamate $(\mathrm{C})$ can be produced in a waterdominated ice from the thermal reaction between carbon dioxide and methylamine. The relative abundance of carbon dioxide on icy grains is about $20 \%$ compared to water (Ehrenfreund \& Charnley 2000; Charnley et al. 2001). Methylamine is observed in the gas-phase of the interstellar medium, and is expected to efficiently condense onto the icy grain surface. Because of its nondetection in solid-state materials with current remote infrared observational techniques, the molar fraction of methylamine in icy grains should be at concentrations of less than $1 \%$ relative to water.

The calculation of Arrhenius parameters $\left(A\right.$ and $\left.E_{a}\right)$ and rate constants $(k)$ relative to the thermal reaction in a waterdominated ice allow us to determine by extropolation the possibility of $\mathrm{C}$ formation in protostellar environments. Table 3 compares the $\mathrm{CO}_{2}$ half-times involved in the reaction with the $\mathrm{CO}_{2}$ residence times onto water ice in the corresponding temperature range (Sandford \& Allamandola 1993). The $\mathrm{CO}_{2}$ half-times are fast in the $50-70 \mathrm{~K}$ temperature range $\left(10^{-2}-10^{-3}\right.$ years) compared to the longer or equivalent $\mathrm{CO}_{2}$ residence time $\left(10^{4}-\right.$ $10^{-3}$ years). The $\mathrm{CO}_{2}$ half-times are also faster than the typical ice lifetime $\left(10^{6}-10^{7}\right.$ years). Methylammonium methylcarbamate $(\mathrm{C})$ is hence likely to be present in the icy grains warmed in the 50-70 K temperature range of protostellar environments. Since cometary ices are related to interstellar ices, the same assumption should be applicable to them. In the hot core regions, temperatures readily exceed $50 \mathrm{~K}$ and are conclusive to $\mathrm{C}$ formation on the icy grains. In the inner protostellar disk, as the temperature decreases in the radial direction, the 50-70 K temperature range corresponds approximatively to 30-15 UA from the young sun (Hayashi 1981). This implies that the icy materials accreted in the 30-15 UA distance range should provide ideal conditions for $\mathrm{C}$ formation. Assuming that the abundance of $\mathrm{CH}_{3} \mathrm{NH}_{2}$ into icy grains is less than $1 \%$ relative to water and that $\mathrm{CH}_{3} \mathrm{NH}_{2}$ is totally consumed in the thermal reaction during the typical ices lifetime, we predict the abundance of $\mathrm{C}$ in icy grains to be less than $0.50 \%$ relative to water. This implies that $\mathrm{C}$ may not be detectable by current remote infrared observational techniques.

Methylammonium methylcarbamate is more refractory than $\mathrm{H}_{2} \mathrm{O}$ or the precursor molecules, implying that it acts as a $\mathrm{CO}_{2}$ and $\mathrm{CH}_{3} \mathrm{NH}_{2}$ molecules reservoir. This could partially explain the $\mathrm{CO}_{2}$ depletion in the protostellar hot core gas (Charnley et al. 2001). Methylammonium methylcarbamate remains stable for a wide range of temperatures but, for $T>240 \mathrm{~K}$, it decomposes successively into methylcarbamic acid $\left(\mathrm{CH}_{3} \mathrm{NHCOOH}\right)$, then into $\mathrm{CH}_{3} \mathrm{NH}_{2}$ and $\mathrm{CO}_{2}$ as clearly illustrated by mass spectrometry by their respective peaks at $m / z=75\left(\mathrm{CH}_{3} \mathrm{NHCOOH}^{+\bullet}\right)$, $m / z=44\left(\mathrm{CO}_{2}^{+\bullet}\right)$, and $m / z=31\left(\mathrm{CH}_{3} \mathrm{NH}_{2}^{+\bullet}\right)$. The instability of methylcarbamic acid $\left(\mathrm{CH}_{3} \mathrm{NHCOOH}\right)$ in the gas phase makes its detection in the interstellar medium difficult by radio astronomy. 
Pure methylammonium methylcarbamate acts as a glycine salt precursor in VUV environments. We determine the yield of the isomerization process induced by ultraviolet photons to be about $32 \%$ in anhydrous conditions. This was inferred independently of the $\mathrm{C}$ thermal formation to facilitate the characterization of the photochemical products. This yield should drastically decline during similar VUV irradiation in a water-dominated ice. The pure $\mathrm{C}$ photolysis is also achieved at $10 \mathrm{~K}$ rather than in the 50-70 K temperature range so as not to combine both irradiation and thermal effects. Since $\mathrm{CH}_{3} \mathrm{NH}_{2}$ and $\mathrm{CO}_{2}$ are primary and secondary photochemical products, respectively, there would be competition between the processes of the thermal formation of $\mathrm{C}$ and its photolysis. This increases the difficulties in both the characterization and the quantitative approach. The 240 min irradiation time corresponds to $\sim 8 \times 10^{6}$ years in a dense cloud (Prasad \& Tarafdar 1983; Gredel et al. 1989). We assume that the upper relative abundance of $\mathrm{C}$ produced in the interstellar ices is $0.50 \%$. During a period of $\sim 8 \times 10^{6}$ years, less than $32 \%$ of $\mathrm{C}$ is converted into $\mathrm{G}$ in anhydrous conditions. We therefore predict that the relative abundance of $\mathrm{G}$ in interstellar ices is lower than $0.16 \%$, and it follows that its direct detection with infrared telescopes should be almost impossible.

In a protostellar environment, the VUV photons emitted from the young stellar object (YSO) are probably sufficient to transform $\mathrm{C}$ into $\mathrm{G}$, before their introduction into comets by icy grains coagulation occurring in the protostellar disk. Comets are then later able to bring prebiotic molecules (amino acids) to primitive earths (Delsemme 1994; Maurette 2006). The glycine salt formation arises inside grains. These grains can then protect $\mathrm{G}$ from the intense UV radiation and ensure that it survives longer. On the other hand, in the star-forming regions, the survival of gaseous phase amino acids is limited to short time (Ehrenfreund et al. 2001b). The radio-astronomical searches of gas phase glycine have therefore been unsuccessful.

Several reactional mechanisms can explain the formation of $\mathrm{G}$ from $\mathrm{C}$ during the VUV irradiation. One of the simplest is summarized in reactions of Eqs. (9), (10), and (11). The first step starts with a carbon-nitrogen bond rupture on methylcarbamate anion $\left[\mathrm{CH}_{3} \mathrm{NHCOO}^{-}\right]$, yielding a carbon dioxide anion radical $\left(\mathrm{CO}_{2}^{-}\right)$and a methyl amino radical $\left(\mathrm{CH}_{3} \mathrm{NH}\right)$. Then a methyl amino radical $\left(\mathrm{CH}_{3} \mathrm{NH}\right)$ rearranges itself into a more stable aminomethyl radical $\left(\mathrm{CH}_{2} \mathrm{NH}_{2}\right)$ (Woon 2002). Finally, glycinate $\left[\mathrm{NH}_{2} \mathrm{CH}_{2} \mathrm{COO}^{-}\right]$formation is achieved by a barrierless radical-radical recombination between a carbon dioxide anion radical $\left(\mathrm{CO}_{2}^{-}\right)$and an aminomethyl radical $\left(\mathrm{CH}_{2} \mathrm{NH}_{2}\right)$.

$\left[\mathrm{CH}_{3} \mathrm{NHCOO}^{-}\right]+h v \rightarrow \mathrm{CH}_{3} \mathrm{NH}+\mathrm{CO}_{2}^{-}$

$\mathrm{CH}_{3} \mathrm{NH} \rightarrow \mathrm{CH}_{2} \mathrm{NH}_{2}$

$\mathrm{CH}_{2} \mathrm{NH}_{2}+\mathrm{CO}_{2}^{-} \rightarrow\left[\mathrm{NH}_{2} \mathrm{CH}_{2} \mathrm{COO}^{-}\right]$.

A comparison can be made between our results and the analysis of cometary grains collected by the Stardust spacecraft ejected from the comet P81/Wild 2. After an acidic hydrolysis procedure, the latter analysis indeed detected traces of methylamine and glycine (Sandford et al. 2006; Glavin 2008). It was also suggested that these freely detected molecules were stored predominantly in an acid-soluble residue before any chemical treatment of the returned samples. This assumption is consistent with our observations of $\mathrm{G}$, which could be one of the acid labile residues that would release free methylamine and free glycine after the chemical treatment of cometary grain samples.

A confirmation of the detection of these molecules and more specifically carbamate or glycinate, should be provided by the ROSETTA mission, including the gas analyser COSAC (COmetary SAmpling and Composition experiment) instrument onboard the lander Philae designed to identify complex organic molecules released from the comet nucleus.

\section{Conclusion}

Icy grains into the ISM can play an important role in prebiotic molecule formation. A glycine isomer salt $\left[\mathrm{CH}_{3} \mathrm{NH}_{3}^{+}\right]\left[\mathrm{CH}_{3} \mathrm{NHCOO}^{-}\right](\mathrm{C})$ is thermally produced from carbon dioxide $\left(\mathrm{CO}_{2}\right)$ and methylamine $\left(\mathrm{CH}_{3} \mathrm{NH}_{2}\right)$. The rate constant in a water-dominated ice is estimated to be $1.1 \times$ $\exp (-3700 / R T)$. This reaction can occur in a $50-70 \mathrm{~K}$ temperature range, which is consistent with protostellar environments. We predict that the upper limit to the abundance of $\mathrm{C}$ produced in the interstellar ices is $0.50 \%$ relative to water. Because of this low abundance and the gas phase decomposition, its detection is therefore impossible by current observational methods.

The identification and the quantitative analysis of the photochemical products yielded during the pure methylammonium methylcarbamate VUV irradiation, are performed independently of its thermal formation. The presence of methylammonium glycinate $\left[\mathrm{CH}_{3} \mathrm{NH}_{3}^{+}\right]\left[\mathrm{NH}_{2} \mathrm{CH}_{2} \mathrm{COO}^{-}\right](\mathrm{G})$ is straightforwardly identified by an in situ analysis. Hence, in a VUV environment, $\left[\mathrm{CH}_{3} \mathrm{NH}_{3}^{+}\right]\left[\mathrm{CH}_{3} \mathrm{NHCOO}^{-}\right]$acts as a glycine salt precursor. We calculated the photolysis yield of $\mathrm{G}$ to be about $32 \%$ in anhydrous conditions. We predict that the abundance of $\mathrm{G}$ produced in the interstellar ices is lower than $0.16 \%$ relative to water. Its detection is also impossible with current observational methods.

We propose a new pathway leading to a glycine salt in interstellar ices. Interstellar glycine might be formed by thermal processing followed by the VUV processing of ices containing carbon dioxide and methylamine. The reactions involved in these processes are summarized below:

$\mathrm{CO}_{2}+2 \mathrm{CH}_{3} \mathrm{NH}_{2} \stackrel{50-70}{\longrightarrow} \mathrm{K}\left[\mathrm{CH}_{3} \mathrm{NH}_{3}^{+}\right]\left[\mathrm{CH}_{3} \mathrm{NHCOO}^{-}\right]$

$\left[\mathrm{CH}_{3} \mathrm{NH}_{3}^{+}\right]\left[\mathrm{CH}_{3} \mathrm{NHCOO}^{-}\right] \stackrel{h v}{\longrightarrow}\left[\mathrm{CH}_{3} \mathrm{NH}_{3}^{+}\right]\left[\mathrm{NH}_{2} \mathrm{CH}_{2} \mathrm{COO}^{-}\right]$.

Our result is consistent with the detection of both glycine and methylamine within the samples returned from comet $81 \mathrm{P} /$ Wild 2. The pathway that we propose originates from in situ experimental evidence and does not need any specific treatment such as water extraction, acid hydrolysis, and derivatization. Methylammonium methylcarbamate or methylammonium glycinate could consist of both interstellar and cometary ices. We believe in the importance of considering thermal processing, VUV photolysis, but also cosmic-ray processing of the interstellar salts that will be produced from the primitive material. Deriving such a chemical scenario on the basis of laboratory work can help astronomers to constrain the sources in which prebiotic molecules could be detected.

Acknowledgements. We thank the PCMI (Physique et Chimie du Milieu Interstellaire) program and also the CNES (Centre National d'Études Spatiales) agency for financial support. The authors would also like to thank Dr. L. Stievano as well as Pr. J. F. Lambert for useful discussions and contributions.

\section{References}

Bernstein, M. P., Dworkin, J. P., Sandford, S. A., Cooper, G. W., \& Allamandola, L. J. 2002, Nature, 416, 401

Bockelée-Morvan, D., Lis, D. C., Wink, J., et al. 2000, A\&A, 353, 1101 
Bossa, J. B., Borget, F., Duvernay, F., Theulé, P., \& Chiavassa, T. 2008a, J. Phys. Chem. A, 112, 5113

Bossa, J. B., Theulé, P., Duvernay, F., Borget, F., \& Chiavassa, T. 2008b, A\&A, 492, 719

Botta, O., \& Bada, J. L. 2002, Surveys in Geophysics, 23, 411

Cabana, A., \& Sandorfy, C. 1962, Spectrochim. Acta, 18, 843

Castellucci, E. 1974, J. Mol. Struct., 23, 449

Cecarelli, C. 2008, International Astronomical Union, Organic Matter in Space, Proc. IAU Symp., 251

Charnley, S. B., Ehrenfreund, P., \& Kuan, Y.-J. 2001, Spectrochim. Acta, Part A, 57A, 685

Cronin, J. R., \& Pizzarello, S. 1997, Science, 275, 951

Crovisier, J. 1998, Faraday Discuss., 109, 437

Crovisier, J., Bockelée-Morvan, D., Colom, P., et al. 2004, A\&A, 418, 1141

Dartois, E. 2005, Space Sci. Rev., 119, 293

DellAmico, D. B., Calderazzo, F., Labella, L., Marchetti, F., \& Pampaloni, G. 2003, Chem. Rev., 103, 3857

Delsemme, A. H. 1994, Adv. Space Res., 15, 49

Despois, D. 1999, Earth Moon Planets, 79, 103

Durig, J. R., Bush, S. F., \& Baglin, F. G. 1968, J. Chem. Phys., 49, 2106

Ehrenfreund, P., \& Charnley, S. B. 2000, ARA\&A, 38, 427

Ehrenfreund, P., Glavin, D. P., Botta, O., Cooper, G., \& Bada, J. L. 2001a, PNAS, 98, 2138

Ehrenfreund, P., Bernstein, M. P., Dworkin, J. P., Sandford, S. A., \& Allamandola, L. J. 2001b, ApJ, 550, L95

Ehrenfreund, P., Irvine, W., Becker, L., et al. 2002, Rep. Progr. Phys., 65, 1427

Elsila, J. E., Dworkin, J. P., Bernstein, M. P., Martin, M. P., \& Sandford, S. A. 2007, ApJ, 660, 911

Fourikis, N., Tagaki, K., \& Morimoto, M. 1974, ApJ, 191, 139

Gardner, E. P., \& McNesby, J. R. 1980, J. Photochem., 13, 353

Glavin, D. P., Dworkin, J. P., \& Sandford, S. A. 2008, Meteoritics \& Planetary Science, 43, 399

Godfrey, P. D., Brown, R. D., Robinson, B. J., \& Sinclair, M. W. 1973, ApL, 13, 119
Gomez-Zavaglia, A., \& Fausto, R. 2003, Phys. Chem. Chem. Phys., 5, 3154

Gredel, R., Lepp, S., Dalgarno, A., \& Herbst, E. 1989, ApJ, 347, 289

Hayashi, C. 1981, Prog. Theo. Phys., 70, 35

Herbst, E. 1985, ApJ, 292, 484

Holtom, P. D., Bennett, C. J., Osamura, Y., Mason, N. J., \& Kaiser, R. I. 2005, ApJ, 626, 940

Irvine, W. M., Schloerb, F. P., Crovisier, J., Fegley, B., \& Mumma, M. J. 2000, Comets: a link between interstellar and nebular chemistry, Protostars and Planets IV, ed. V. Manning, A. Boss, \& S. Russell (Tucson: University of Arizona Press)

Kaifu, N., Morimoto, M., Nagane, K., et al. 1974, ApJ, 191, 135

Kuan, Y. J., Charnley, S. B., Huang, H. C., Tseng, W. L., \& Kisiel, Z. 2003, ApJ, 593, 848

Kvenvolden, K., Lawless, J., Pering, K., et al. 1970, Nature, 288, 923

Lafosse, A., Bertin, M., Domaracka, A., et al. 2006, Phys. Chem. Chem. Phys., 8,5564

Lawless, J., Kvenvolden, K. A., Peterson, E., Ponnamperuma, C., \& Jarosewich, E. 1972, Nature, 236, 66

Lee, C. W., Kim, J. K., Moon, E. S., Minh, Y. C., \& Kang, H. 2009, ApJ, 697, 428

Maurette, M. 2006, Micrometeorites and the mysteries of our origins, Advances in Astrobiology and Biogeophysics (Berlin, Heidelberg, New York: Springer)

Munoz Caro, G. M., Meierhenrich, U. J., Schutte, W. A., et al. 2002, Nature, 416, 403

Oeberg, K. I., Fraser, H. J., Boogert, A. C. A., et al. 2007, A\&A, 462, 1187

Ogura, K., Migita, C. T., \& Yamada, T. 1988, Chem. Lett., 1563

Prasad, S., \& Tarafdar, S. P. 1983, ApJ, 267, 603

Rosado, M. T., Duarte, M. L. T. S., \& Fausto, R. 1998, Vib. Spectrosc., 16, 35

Sandford, S. A., \& Allamandola, L. J. 1993, ApJ, 417, 815

Sandford, S. A., Aleon, J., Alexander, C. M. O'D, et al. 2006, Science, 314, 1720

Schutte, W. A., \& Gerakines, P. A. 1995, Planet. Space Sci., 43, 1253

Snyder, L. E., Lovas, F. J., Hollis, J. M., et al. 2005, ApJ, 619, 914

Waldron, R. D. 1953, J. Chem. Phys., 21, 734

Woon, D. E. 2002, ApJ, 571, 177 